\title{
Modification of Alloy 706 for High Temperature Steam Turbine Rotor Application
}

\author{
Shinya Imano ${ }^{1}$, Hiroyuki Doi ${ }^{1}$, \\ Koji Kajikawa ${ }^{2}$ and Tatsuya Takahashi ${ }^{2}$ \\ ${ }^{1}$ Hitachi Research Laboratory, Hitachi, LTD.; \\ 1-1-7 Omika-cho, Hitachi, Ibaraki, 319-1292, Japan \\ ${ }^{2}$ Muroran Research Laboratory, The Japan Steel Works, LTD.; \\ 4 Chatsu-Machi, Muroran, Hokkaido, 051-8505, Japan \\ Keywords: Alloy706, $700{ }^{\circ} \mathrm{C}$ USC, Steam Turbine Rotor, FENIX-700
}

\begin{abstract}
To improve microstructure stability at temperatures up to $700^{\circ} \mathrm{C}$ and avoid segregation of $\mathrm{Nb}$, we modified the chemical composition of Alloy706. It is known that Alloy706 is strengthened by $\gamma^{\prime}\left(\mathrm{Ni}_{3} \mathrm{Al}\right)$ phase and $\gamma^{\prime}$ ' $\left(\mathrm{Ni}_{3} \mathrm{Nb}\right)$ phase. But these phases are unstable at high temperatures after long-term exposure and transform into $\mathrm{Nb}$ rich $\delta$ or $\eta$ phase. The modified alloy (FENIX-700) contains less $\mathrm{Nb}$ and more $\mathrm{Al}$ than Alloy706, so it is strengthened only by $\gamma^{\prime}\left(\mathrm{Ni}_{3} \mathrm{Al}\right)$ phase. Also, we could not find $\delta$ or $\eta$ phase in the FENIX-700 after creep and aging at $700^{\circ} \mathrm{C}$. The tensile strengths of the FENIX-700 at temperatures from room temperature to $700^{\circ} \mathrm{C}$ are almost the same as that of Alloy706. The yield strength of FENIX-700 at room temperature is slightly lower than that of Alloy706, but equivalent to that of Alloy706 at high temperatures. The tensile and yield strengths of FENIX-700 at temperatures from room temperature to $700^{\circ} \mathrm{C}$ are higher than that of Alloy 706 after aging at $700^{\circ} \mathrm{C}$. According to $10^{4} \mathrm{~h}$ class creep tests, the approximate $10^{5} \mathrm{~h}$ creep strength of FENIX-700 at $700^{\circ} \mathrm{C}$ is more than $100 \mathrm{MPa}$. In this presentation, we use mechanical testing, TEM observation, a segregation test and thermodynamics calculation results to show the mechanical properties and advantages of FENIX-700 for high temperature steam turbine applications.
\end{abstract}




\section{Introduction}

In order to further improve thermal efficiency, ultra super critical steam turbines with main steam temperatures of $700^{\circ} \mathrm{C}$ or more (A-USC) are under development (e.g., the "Advanced $\left(700^{\circ} \mathrm{C}\right)$ PF Power Plant" Project carried out under The EC Research And Technological Development Program (THERMIE))). Conventional rotor materials made of ferritic steel are not suitable for A-USC rotors since their maximum temperature is limited to $650^{\circ} \mathrm{C}$, and thus, it is necessary to produce the rotor from high strength $\mathrm{Ni}$ base or Ni-Fe base super alloy. Ni-36Fe$16 \mathrm{Cr}-3 \mathrm{Nb}-1.7 \mathrm{Ti}-0.3 \mathrm{Al}$ (Alloy706 ${ }^{1) 2}$ ) is advantageous because it is excellent in terms of its large steel ingot manufacturing properties, strength and cost (contains about 40 weight percent of $\mathrm{Fe}$ ). Alloy706 is a gas-turbine disk material. However, since Alloy706 suffers from a solidification defect (freckle defect) due to segregation of $\mathrm{Nb}$, it is difficult to make a forged product exceeding 10 tons in weight from Alloy706. In order to improve the manufacturing properties of the large alloy ingots, it is useful to reduce $\mathrm{Nb}$, which is a segregation element. However, since Alloy706 is precipitation-strengthened by $\mathrm{Ni}_{3} \mathrm{Nb}\left(\gamma^{\prime \prime}\right.$ Phase $)$ and $\mathrm{Ni}_{3} \mathrm{Al}\left(\gamma^{\prime} \text { Phase }\right)^{3)}$, its strength is deteriorated if the $\mathrm{Nb}$ concentration is reduced. Also, it is known that harmful phases are precipitated when Alloy 706 is subjected to $700^{\circ} \mathrm{C}$ for a long time ${ }^{2)}$, and the $\mathrm{Ni}-\mathrm{Fe}$ base superalloy is thereby weakened. As described above, in the case of manufacturing a steam turbine whose main steam temperature is over $700^{\circ} \mathrm{C}$, there has been a problem with respect to the manufacturing properties and high-temperature microstructure stability of the rotor material. To solve these problems we modified the chemical composition of Alloy706 using CALPHAD method $^{4)}$ and experimental data.

\section{Experimental Procedure}

Microstructure observation and tensile tests

Table 1 shows the chemical composition of the specimens used in the tensile tests (Alloy706, FENIX-700T). These specimens were machined from forged bars $(30 \mathrm{~mm} \times 30 \mathrm{~m} \times \mathrm{L})$, which were made from VIM $(20 \mathrm{~kg})$ ingots. The forged bars were solution treated at $995^{\circ} \mathrm{C}$ and water quenched. After the solution treatment, the forged bars were aged at $732^{\circ} \mathrm{C}$ for $8 \mathrm{~h}$, and then furnace cooled to $621^{\circ} \mathrm{C}$ and aged at $621^{\circ} \mathrm{C}$ for $8 \mathrm{~h}$. Tensile tests and microstructure observations (TEM) were performed using these specimens. Tensile tests and v-notched Charpy energy tests were performed after long-term aging at $700^{\circ} \mathrm{C}$ for $3000 \mathrm{~h}$.

\section{Creep rupture tests}

Creep tests were performed at $700^{\circ} \mathrm{C}$ and $750^{\circ} \mathrm{C}$. Table 1 shows the chemical composition of the specimens (FENIX-700C). These specimens were machined from forged bars $(30 \mathrm{~mm} \times 30 \mathrm{~m} \times \mathrm{L})$, which were made from VIM $(10 \mathrm{~kg})$ ingots. The forged bars were solution treated at $982^{\circ} \mathrm{C}$ and air cooled to room temperature. After the solution treatment, the forged bars were aged the same way as the specimens for the tensile tests. The grain numbers of these specimens were 3 to 3.5 .

\section{$\underline{\text { Segregation Test }}$}

It is reported that there is a critical value for macro segregation $\left(\varepsilon R^{1.1}{ }_{C}{ }^{5)}\right.$ which is a function of cooling rate $(\varepsilon)$ and solidification rate $(\mathrm{R})$. To prevent macro segregation, it is necessary to maintain the $\varepsilon \mathrm{R}^{1.1}$ value higher than $\varepsilon \mathrm{R}^{1.1}{ }_{\mathrm{C}}$ during the solidification process. The critical value 
for segregation depends on the chemical composition of the alloys. It is effective to reduce $\varepsilon$ $\mathrm{R}^{1.1}{ }_{\mathrm{C}}$ to avoid segregation during ESR or VAR processes.

To evaluate $\varepsilon \mathrm{R}^{1.1}$ of FENIX-700 and compare it to Alloy706, segregation tests were performed using a horizontal directional solidification furnace which is shown in Figure 1. Temperatures were measured at six points, from casting to the end of solidification. Cooling rate ( $\varepsilon$ ) and solidification rate $(R)$ were evaluated from these data at each point. The value of $\varepsilon R^{1.1}$ is evaluated as a function of distance from cooling chill. A macrostructure observation was performed using the specimens after solidification to determine the distance from the cooling chill to the first segregation point. Critical values for segregation $\left(\varepsilon R^{1.1}{ }_{C}\right)$ are determined using the distance from the cooling chill to the first segregation point and previous function. Table 2 shows the chemical composition of the ingots after the segregation test.

\section{Result and Discussion}

Design philosophy and chemical composition of FENIX-700

The purpose of the modification is to improve the microstructure stability and segregation properties of the alloy, and our goal is to develop 10ton class forging with adequate long term strength for A-USC steam turbine rotors without segregation defects. To improve the segregation property, the amount of $\mathrm{Nb}$ is decreased to about $2 \mathrm{wt} \%$ from $3 \mathrm{wt} \%$. Because $\mathrm{Nb}$ is a heavy element and a strong segregation element which accelerates sinking type macro segregation, it is also effective to increase light and segregation elements such as $\mathrm{Al}$ and $\mathrm{Ti}$ in order to avoid sinking type macro segregation. But increasing Ti is bad for the microstructure stability, because $\mathrm{Ti}$ is an $\eta$ phase former. Figure 2 shows the calculation result of phase equilibria of Alloy 706 at $700^{\circ} \mathrm{C}$. According to this result, $\gamma^{\prime}$ phase can be stabilized by the reduction of $\mathrm{Nb}$ and the addition of $\mathrm{Al}$. Al addition is not effective to increase the yield stress below $400^{\circ} \mathrm{C}$, because the amount of $\gamma$ ' phase, which is the most effective phase to increase yield stress at lower temperature is reduced by $\mathrm{Al}$ addition despite the increase in $\gamma^{\prime}$. However, it is effective to increase yield stress above $600^{\circ} \mathrm{C}$. The amount of $\mathrm{Al}$ is increased to about $1.2 \mathrm{wt} \%$ to improve the microstructure stability and to compensate for the high temperature strength degradation caused by the $\mathrm{Nb}$ reduction. The addition of $\mathrm{Al}$ is also effective in improving the segregation properties. Table 1 shows the chemical composition of FENIX-700 which is the candidate material for A-USC steam turbine rotors.

\section{Microstructure and mechanical properties of FENIX-700}

Photo 1 shows the TEM images of FENIX-700 and Alloy700. The $\gamma$ ' 'phase was observed in Alloy706, but there was no $\gamma$ ' 'phase in FENIX-700 and we could find only spherical $\gamma$ 'phase. Figure 3 shows the result of the tensile tests of FENIX-700 and Alloy706. The tensile strengths of FENIX-700 at temperatures from room temperature to $700^{\circ} \mathrm{C}$ were almost the same as those of Alloy706. The yield strength of FENIX-700 at room temperature was slightly lower than that of Alloy706, but equivalent to that of Alloy706 at higher temperatures.

Photo 2 shows the TEM images of FENIX-700 and Alloy706 after aging for 3000h at $700^{\circ} \mathrm{C}$. The $\gamma^{\prime}$ 'phase and platelet and needle shape precipitates were observed in the Alloy 706 after aging. They were $\eta$ or $\delta$ phase, but we could not distinguish these phases exactly, because their diffraction patterns are similar. Only $\gamma$ 'phase was observed and we could not find platelet or needle shape precipitates in the FENIX-700 after aging. These phases were not observed in the creep ruptured specimen'. Figure 4-1 shows the tensile properties after aging at $700^{\circ} \mathrm{C}$ for $3000 \mathrm{~h}$. Degradations of $0.2 \%$ yield strength and tensile strength at room temperature of Alloy 706 were observed, but those of FENIX-700 were negligibly small. Figure 4-2 shows the result of the vnotched Charpy impact test after aging at $700^{\circ} \mathrm{C}$ for $3000 \mathrm{~h}$. Degradation of Charpy impact energy after aging was obvious for Alloy706, and negligible for FENIX-700. It is clear that the 
degradation of mechanical properties after aging at $700^{\circ} \mathrm{C}$ is due to microstructure degradation in Alloy706. We consider that the superior microstructure stability of FENIX-700 is the advantage for the prevention of mechanical property degradation and improvement in long-term creep rupture strength.

Figure 5 shows the LMP plot of creep rupture time. Open symbols are the data of non-ruptured specimens (more than $8000 \mathrm{~h}$ ). According to the creep strain data, the creep specimen is in the third stage and about to rupture. Degradation of creep rupture strength was not observed according to $10^{4} \mathrm{~h}$ class creep rupture test at $700^{\circ} \mathrm{C}$. The approximate $10^{5} \mathrm{~h}$ creep strength of FENIX-700 at $700^{\circ} \mathrm{C}$ using the LMP method $(\mathrm{C}=20)$ is more than $100 \mathrm{MPa}$ which is adequate for a steam turbine rotor material.

\section{$\underline{\text { Segregation behavior and limit of ingot size }}$}

Figure 6 shows the result of temperature measurements from Point 1 to Point 6 after casting. According to these results, the cooling rate and solidification speeds were calculated at each point. Figure 7 shows the cross section of specimen Ch.1 after the segregation test. Segregation defects in the $\mathrm{Nb}$ rich region were observed $50 \mathrm{~mm}$ from the cooling side. The critical values for segregation $\left(\varepsilon \mathrm{R}^{1.1}\right.$ ) are evaluated from the cooling rate $(\varepsilon)$ and solidification speed $(\mathrm{R})$. Figure 8 shows the relationship between the critical value for segregation and the distance from the cooling side (Ch.1). The critical value for segregation is evaluated from these result . Table 3 shows the critical values for segregation of Ch.1, Ch. 2 and Alloy $706^{6}$. The limit of ingot size depends on the minimum value of $\varepsilon \mathrm{R}^{1.1}$ during the remelting process and on the $\varepsilon \mathrm{R}^{1.1}$ c value of the material. Figure 9 shows the relationship between the minimum value of $\varepsilon \mathrm{R}^{1.1}$ during the remelting process and the ingot diameter according to the ESR process simulation. According to these results, the limits of ingot diameter were evaluated as shown in Table 3. The limit of ingot size for FENIX-700 is larger than that of Alloy 706. It is expected that larger ingots can be made from FENIX-700 by optimizing the ingot making process and minor modifications of the chemical composition.

\section{Conclusion}

To improve the microstructure stability and segregation properties, and to develop 10ton class forging with adequate long term strength for A-USC steam turbine rotors without segregation defects, we modified the chemical composition of Alloy706. Following are the conclusions according to the results of our investigation of modified alloy FENIX-700.

1. FENIX-700 is a $\gamma^{\prime}$ phase strengthened alloy without $\gamma^{\prime}$ ' phase and has superior microstructure stability to Alloy 706 at $700^{\circ} \mathrm{C}$.

2. The tensile properties of FENIX-700 are equivalent to those of Alloy 706 at $700^{\circ} \mathrm{C}$, and the approximate $10^{5} \mathrm{~h}$ creep strength at $700^{\circ} \mathrm{C}$ is higher than $100 \mathrm{MPa}$ according to $10^{4} \mathrm{~h}$ class creep tests.

3. The ingot size limit of FENIX-700 due to segregation problems is larger than that of Alloy706 according to segregation tests and ESR process simulations. 


\section{Acknowledgements}

The authors would like to thank Dr. Takashi Shibata for his advice on ingot making and on the forging process of superalloys from the early stage of this development.

\section{References}

1. C. Berger, J. Granacher, A. Thoma, Proc.Conf. Superalloys 718, 625, 706 and Various Derivatives, 2001, 489-499.

2. H. J. Penkalla, J. Wosik, W. Fischer, F. Schubert, Proc.Conf. Superalloys 718, 625, 706 and Various Derivatives, 2001, 279-290.

3. T. Takahashi,T. Shibata:CAMP-ISIJ VOL.10(1997)- 1414

4. N. Saunders, X. Li, A. P. Miodownik and J-Ph. Proc. Symp. Materials Design Approaches and Experiences, eds. J.-C. Shao et al., 185-197;2001, Warrendale, PA, TMS.

5. K. Suzuki and T. Miyamoto: Trans. ISIJ, 1978, 18(2), pp.80-89

6. A. Itoh, S. Suzuki, K. Kajikawa and H. Yamada: JSW technical review(Japanese) 54 (1998) pp.104-112)

Table 1 Chemical Composition of the Specimens(wt $\%$ )

\begin{tabular}{lccccccc}
\hline & $\mathrm{C}$ & $\mathrm{Ni}$ & $\mathrm{Cr}$ & $\mathrm{Fe}$ & $\mathrm{Al}$ & $\mathrm{Ti}$ & $\mathrm{Nb}$ \\
\hline Alloy706 & 0.03 & 41.3 & 16.00 & Bal. & 0.3 & 1.70 & 2.9 \\
\hline FENIX700T & 0.03 & 41.4 & 15.60 & Bal. & 1.26 & 1.70 & 2.0 \\
\hline FENIX700C & 0.03 & 41.0 & 15.40 & Bal. & 1.25 & 1.73 & 2.0 \\
\hline
\end{tabular}

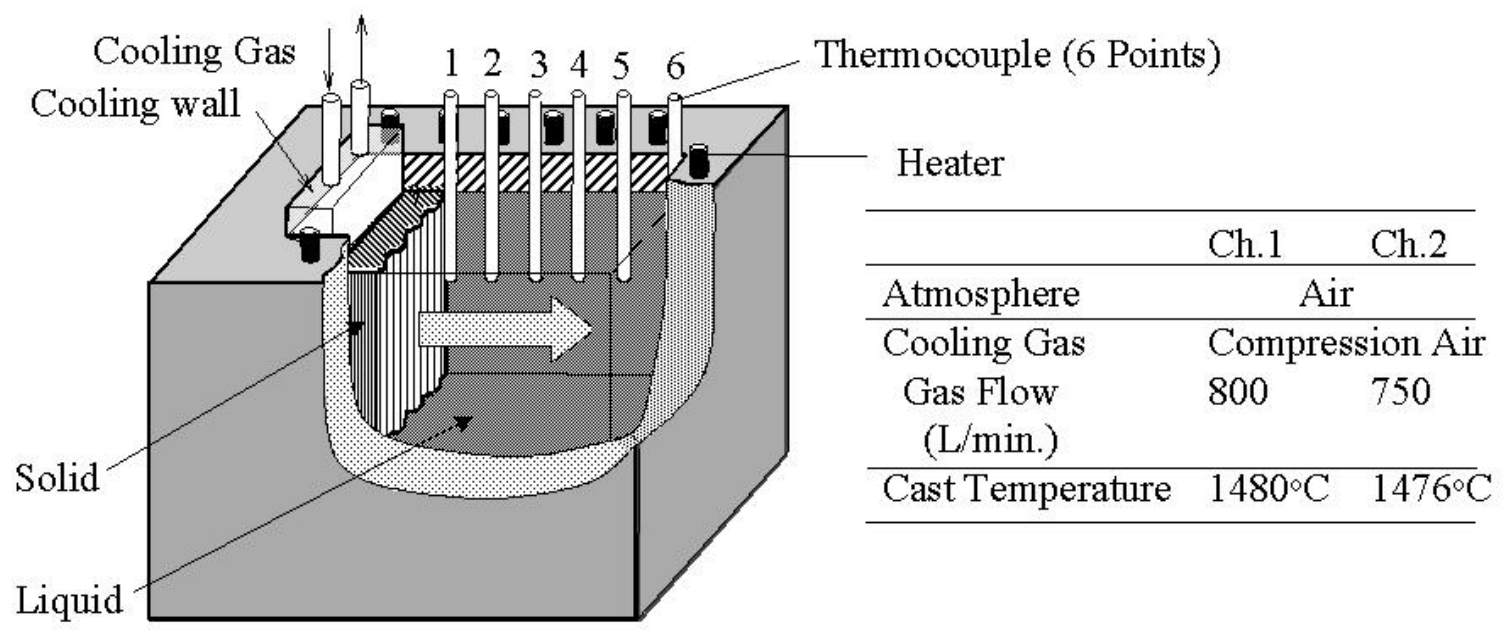

Figure 1 Horizontal Directional Solidification Furnace

Table 2 Chemical Composition of Specimens used in Segregation Tests (wt \%)

\begin{tabular}{ccccccccccc}
\hline & $\mathrm{C}$ & $\mathrm{Si}$ & $\mathrm{Ni}$ & $\mathrm{Cr}$ & $\mathrm{Fe}$ & $\mathrm{Al}$ & $\mathrm{Ti}$ & $\mathrm{Nb}$ & $\mathrm{O}(\mathrm{ppm})$ & $\mathrm{N}(\mathrm{ppm})$ \\
\hline $\mathrm{Ch} .1$ & 0.003 & 0.01 & 41.16 & 15.90 & 35.80 & 2.10 & 2.54 & 2.06 & 13 & 102 \\
\hline $\mathrm{Ch} .2$ & 0.005 & 0.04 & 42.70 & 15.44 & 36.59 & 1.23 & 1.82 & 2.11 & 7 & 72 \\
\hline
\end{tabular}




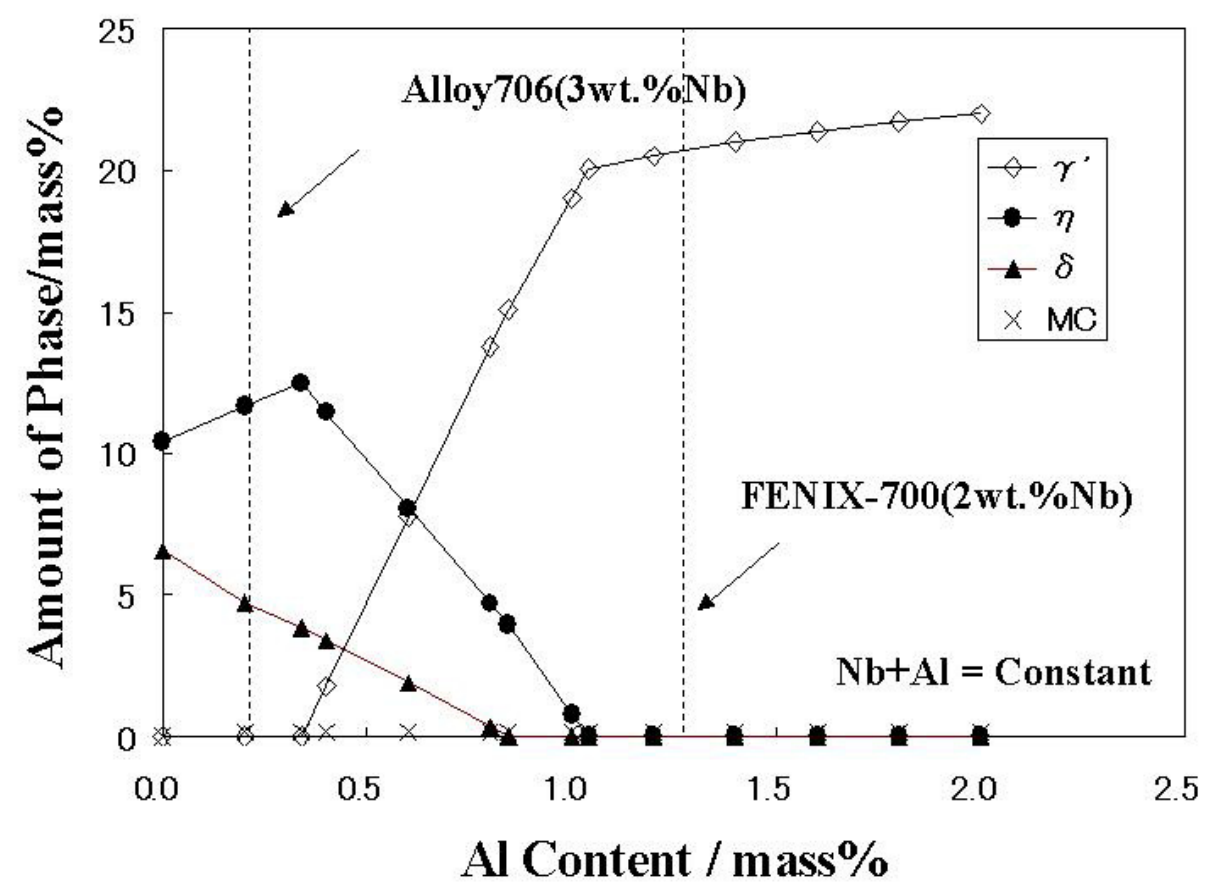

Figure 2 Calculation Results of Phase Equilibria at $700^{\circ} \mathrm{C}$
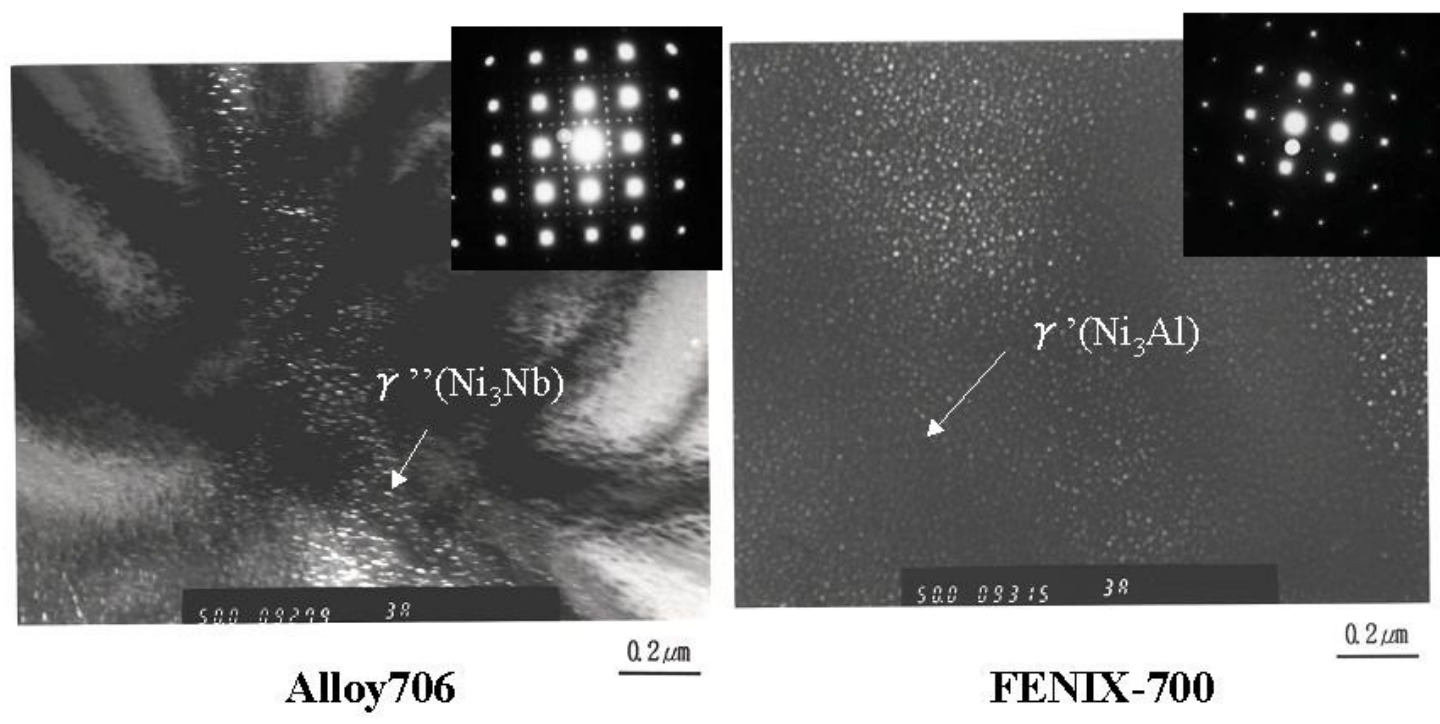

Photo 1 TEM images of Alloy706 and FENIX-700 


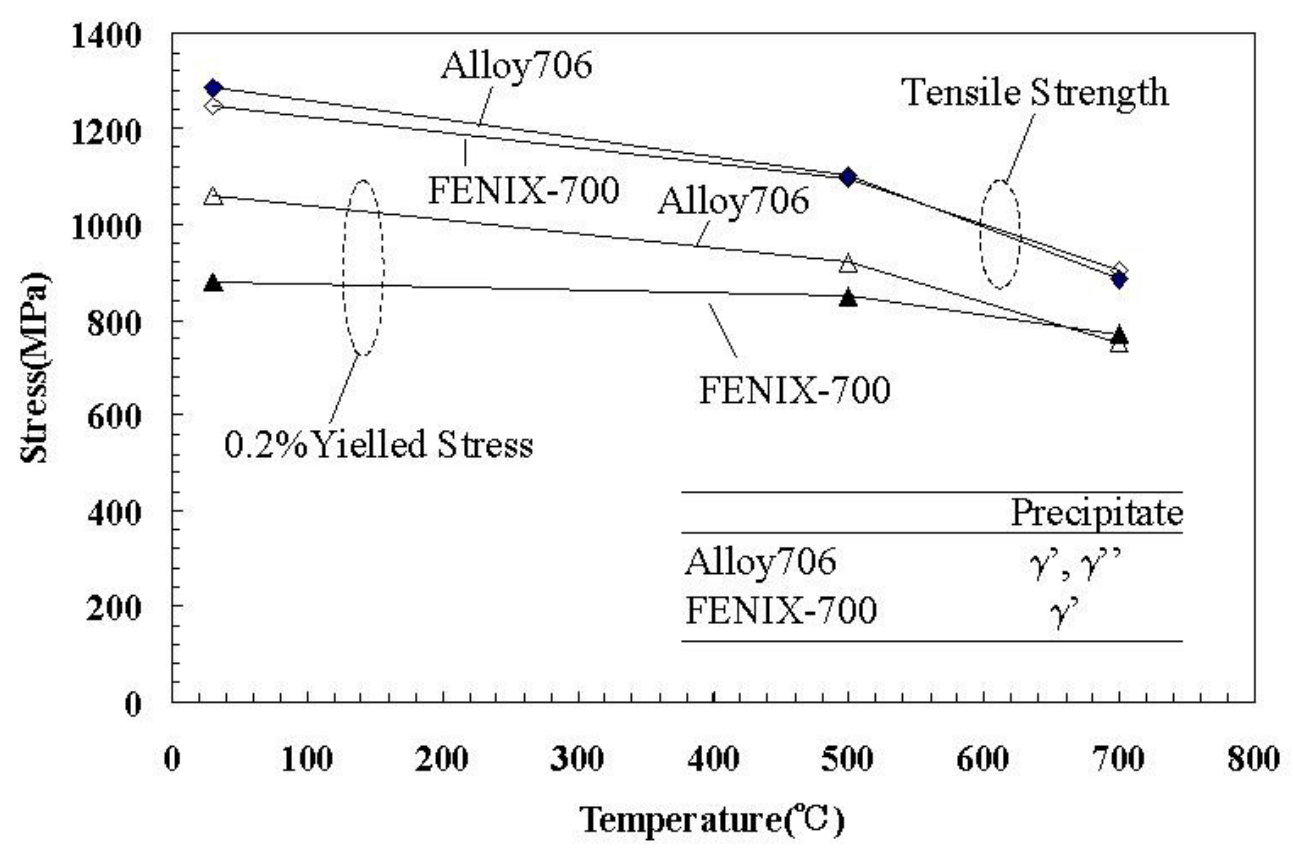

Figure 3 Comparison of Tensile Properties of Alloy706 and FENIX-700
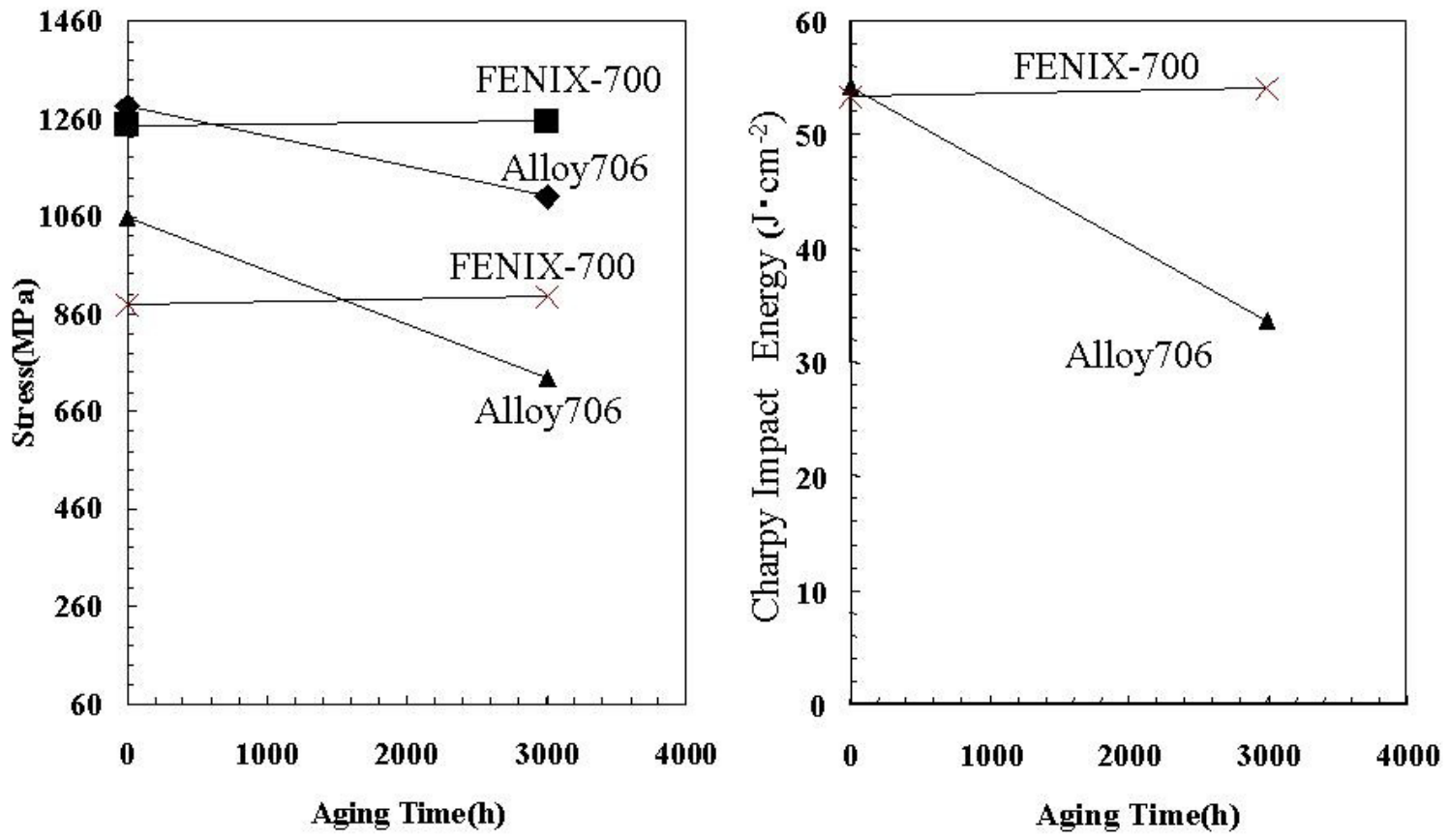

Figure 4 Results of Charpy Impact and Tensile Test of Aged Specimens $\left(700^{\circ} \mathrm{C}, 3000 \mathrm{~h}\right)$ 

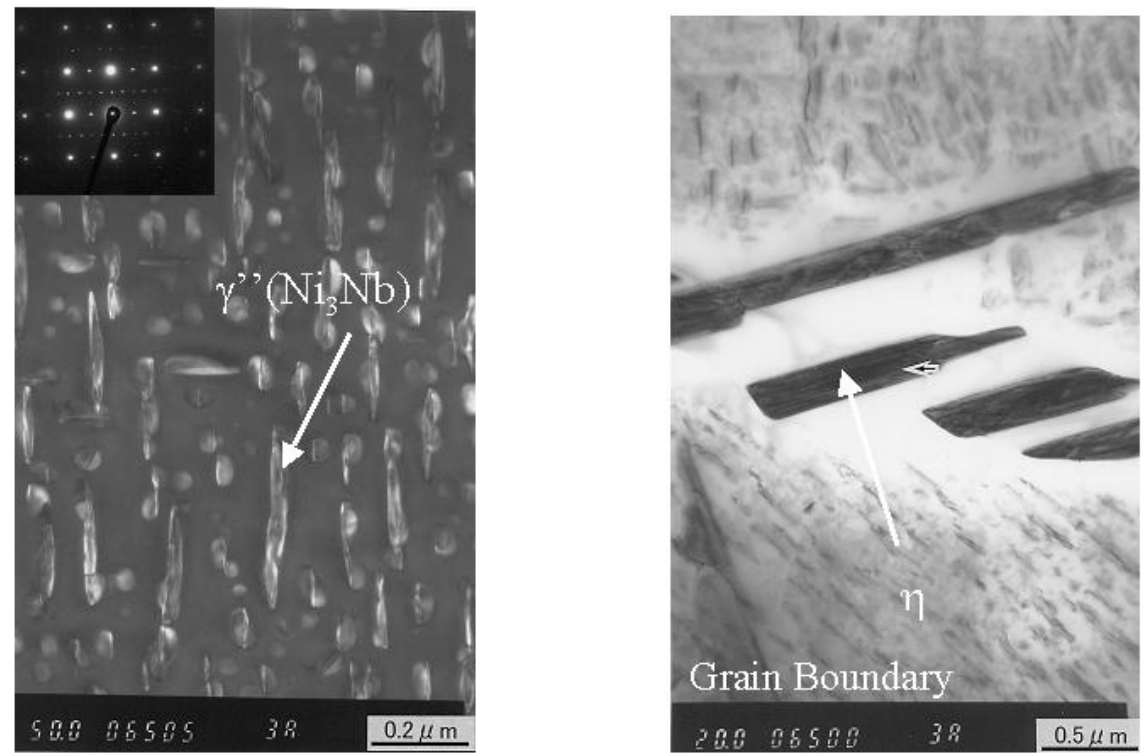

Photo 2-1 TEM image of Alloy 706 after aging at $700^{\circ} \mathrm{C}, 3000 \mathrm{~h}$
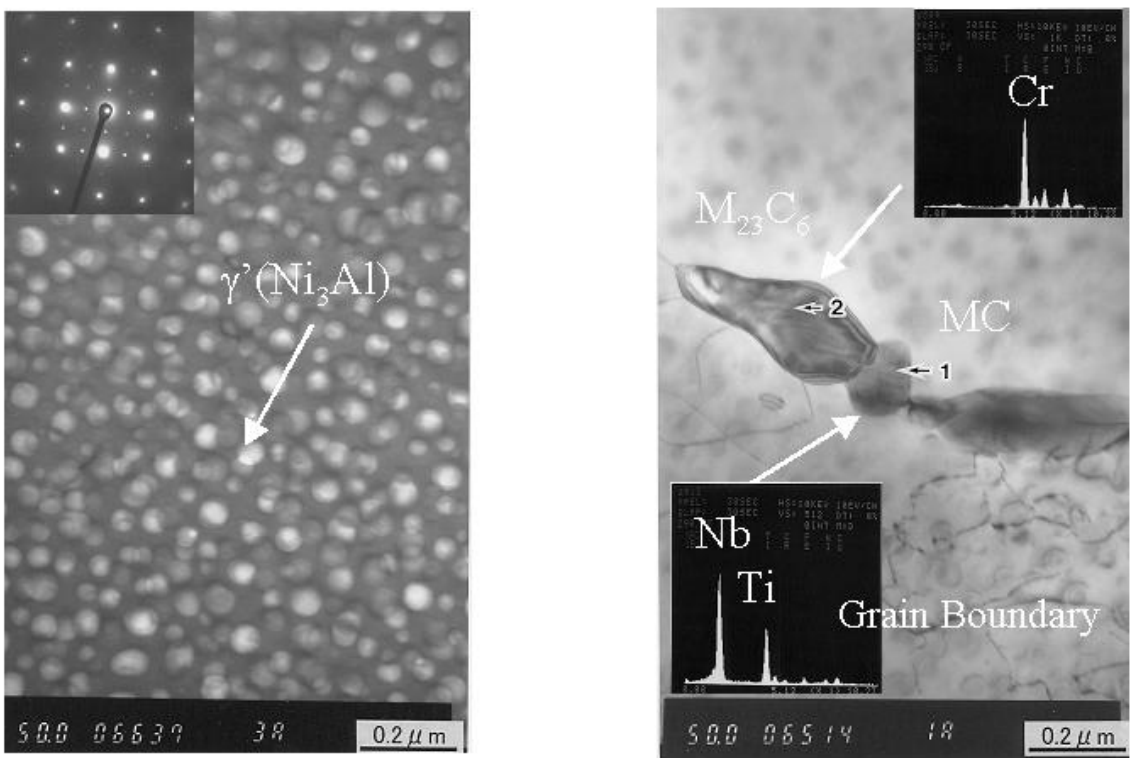

Photo 2-2 TEM image of FENIX-700 after aging at $700^{\circ} \mathrm{C}, 3000 \mathrm{~h}$ 


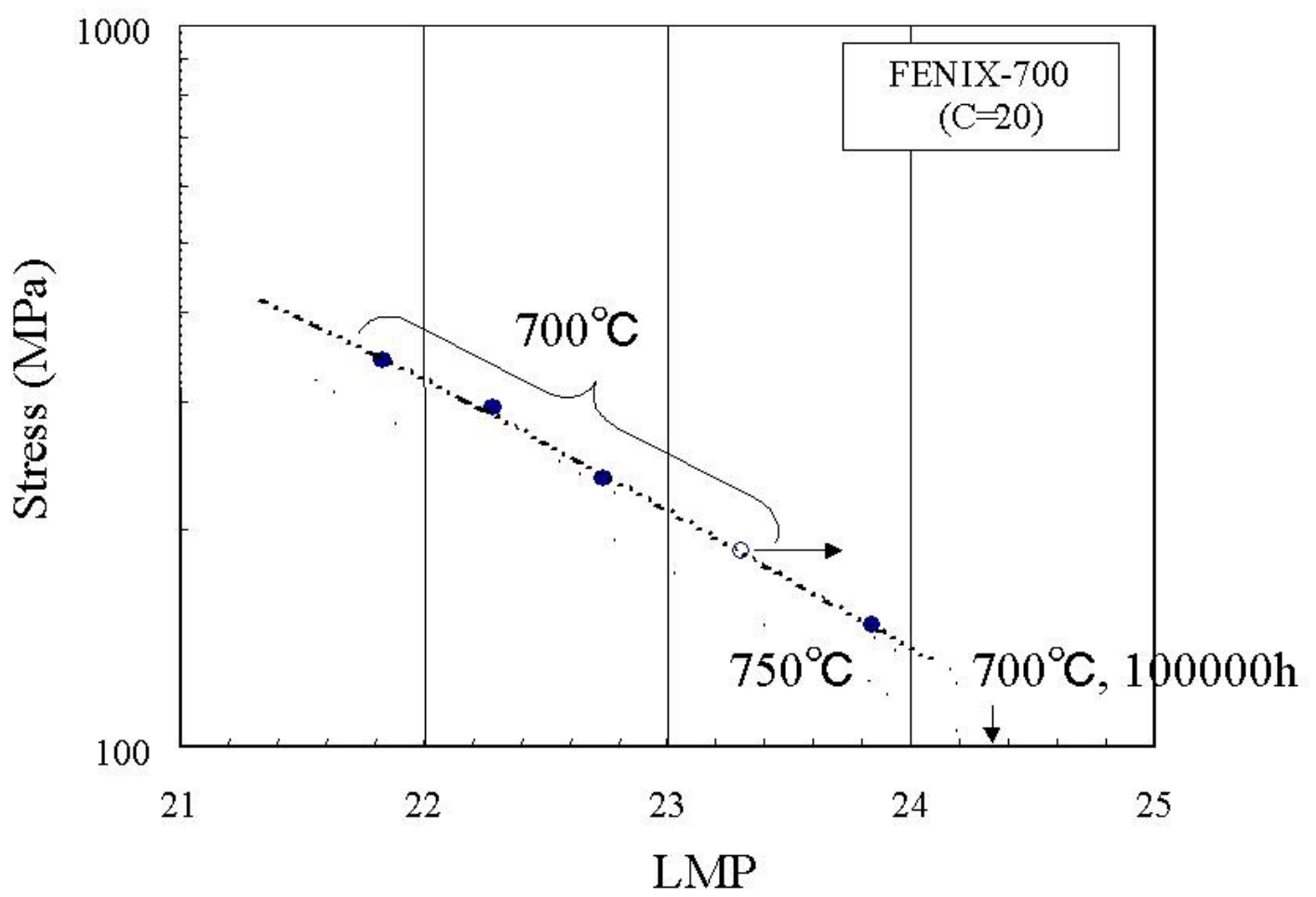

Figure 5 Results of Creep Rupture Tests at $700^{\circ} \mathrm{C}$ and $750^{\circ} \mathrm{C}$
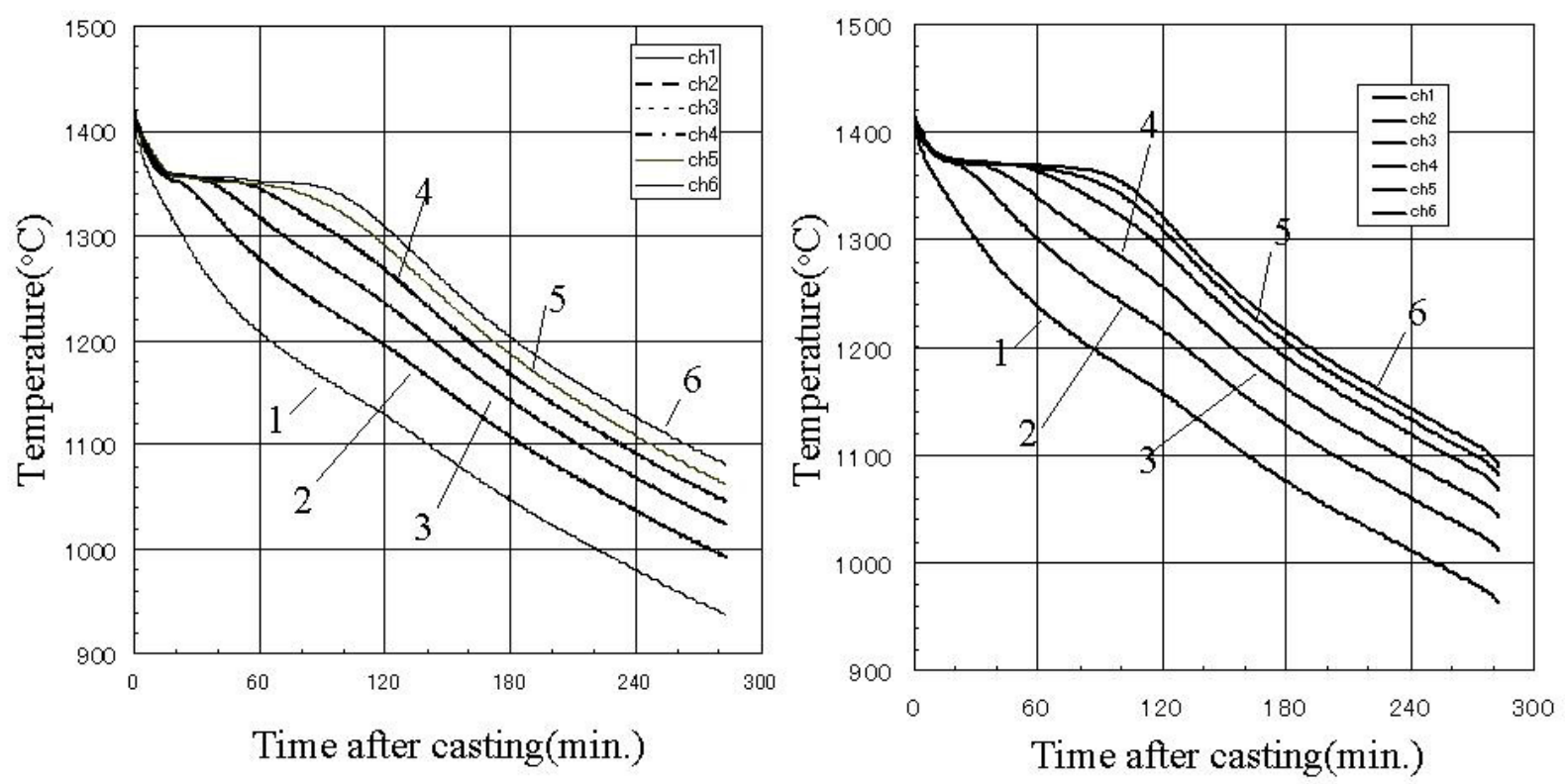

Figure 6 Results of Segregation Tests (Variation of Temperature at pointl to point6) 


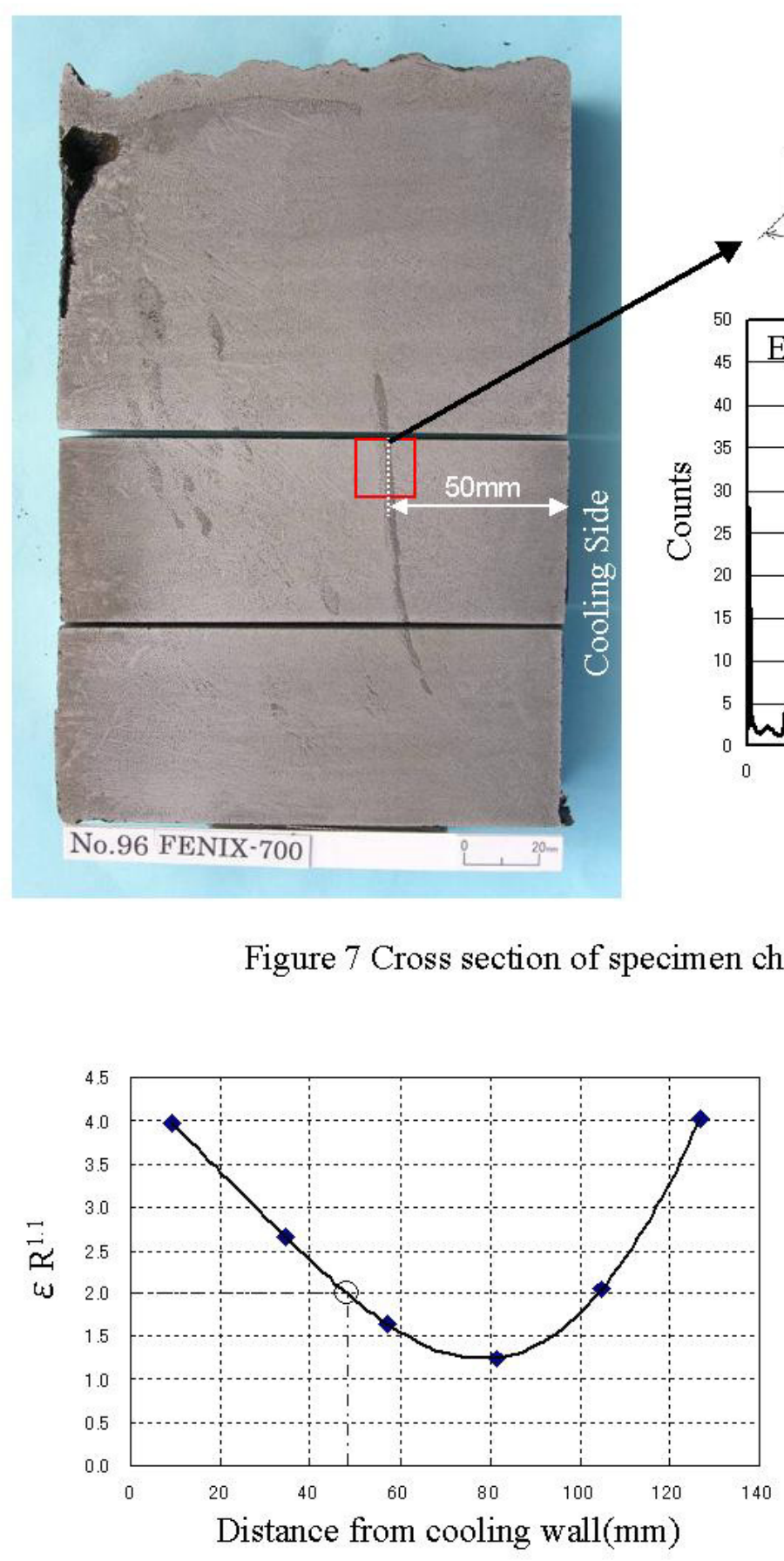

Figure 8 Variation of $\varepsilon \mathrm{R}^{1.1}$ during solidification

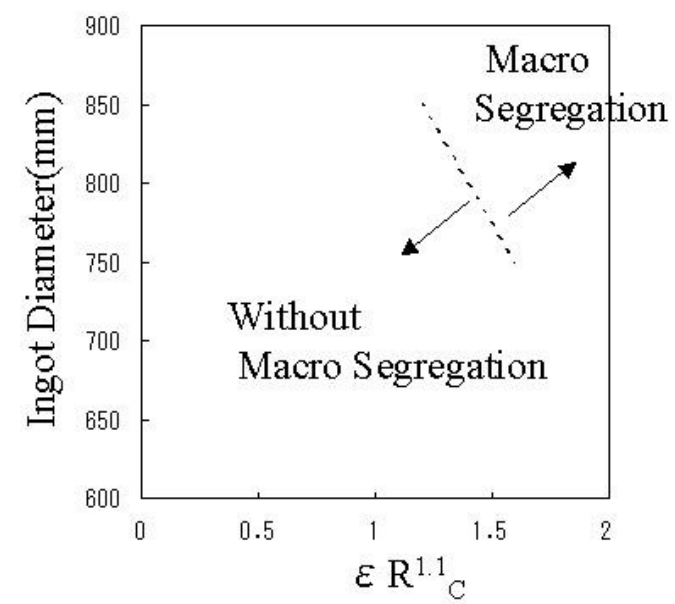

Figure 9 Result of ESR simulation

Table 3 Comparison of Maximum Diameter of ESR Ingots

\begin{tabular}{lccc}
\hline & Segregation point $(\mathrm{mm})^{* *}$ & $\varepsilon \mathrm{R}^{1.1}{ }_{\mathrm{C}}$ & Approximate Max. Dia. $^{*}$ \\
\hline Alloy706 & --- & $1.60^{6)}$ & $750 \mathrm{~mm}$ \\
Ch.1 & 50 & 2.00 & $<750 \mathrm{~mm}$ \\
Ch.2*** & 80 & 1.17 & $850 \mathrm{~mm}$ \\
\hline
\end{tabular}

*Evaluated from Fig.9 *** Distance from cooling wall to first segregation point *** Similar to chemical composition of FENIX-700 